\title{
Geographic and seasonal variations in the surface properties of the ice sheets by satellite-radar altimetry
}

\author{
Gurt H. Davis \\ Electrical and Computer Engineering, University of Missouri-Truman Campus, Independence, Missouri 64050, U.S.A. \\ H. JAY ZWALLY \\ NASA/Goddard Space Flight Center, Oceans and Ice Branch, Code 971, Greenbelt, Maryland 20771, U.S.A.
}

\begin{abstract}
Geosat-altimeter wave forms from the Greenland and Antarctic ice sheets are analyzed using an algorithm based upon a combined surface- and volumescattering model. The results demonstrate that sub-surface volume-scattering occurs over major parts of the ice sheets. Quantitative estimates of geographic variations in the near-surface ice-sheet properties are derived by retracking individual altimeter wave forms. The derived surface properties correlate with elevation, latitude and microwave brightness-temperature data. Specifically, the extinction coefficient of snow obtained by this method varies from 0.48 to $0.13 \mathrm{~m}^{-1}$ over the latitudes from $65^{\circ}$ to $72^{\circ} \mathrm{N}$ on the central part of the Greenland ice sheet and from 0.20 to $0.10 \mathrm{~m}^{-1}$ over a section of Wilkes Land in East Antarctica where the elevation increases from 2550 to $3150 \mathrm{~m}$.

Analysis of passive-microwave data over East Antarctica shows that the brightness temperature increases with elevation as the extinction coefficient decreases. Larger snow grain-sizes occur at lower elevations of the ice sheet because of higher mean annual temperatures. The larger grain-sizes increase the extinction coefficient of snow and decrease the emitted energy (brightness temperature) from greater snow depths. The passive-microwave data are also used to determine the average number of melt d year ${ }^{-1}(1979-87)$ for the central part of the Greenland ice sheet. For latitudes from $65^{\circ}$ to $68.5^{\circ} \mathrm{N}$, the average number of melt days decreases from 3.5 to $0.25 \mathrm{~d}$ year $^{-1}$, whereas no melt events are observed for latitudes above $69^{\circ} \mathrm{N}$ over the 8 year period. Snow subjected to alternate melting and freezing has enhanced grainsizes compared to that of dry snow. This accounts for the larger values and larger spatial variations of $k_{\mathrm{e}}$ on the Greenland ice sheet compared to East Antarctica, where surface temperatures are never high enough to cause surface melting.
\end{abstract}

\section{INTRODUCTION}

The development of space-borne radar altimeters has opened a new era in which observations of the Earth's oceans and ice sheets can be carried out on a global scale. The microwave radar altimeter is conceptually the simplest of active remote-sensing instruments, and, after nearly two decades of space-borne operation, it has become a well-developed and documented tool. The primary purpose for the development of space-borne altimetry was oceanic physics, where altimeters were proposed for the measurement of mean sea level and sea state. The first space-borne radar altimeter was flown in 1973 aboard Skylab (McGoogan and others, 1974). It provided the experimental data that showed that meaningful oceanographic and geodetic information could be obtained from a space-borne platform. The Geos-3 altimeter (Stanley, 1979) operated from 1975 to 1978 and provided the spatial and temporal coverage necessary for detailed oceanographic studies. The Seasat altimeter (Townsend, 1980), which operated for 3 months in 1978 and then failed, is widely recognized as having made the greatest impact on the fields of oceanography and geodesy. From an orbiting altitude of $800 \mathrm{~km}$, it achieved a range precision of $10 \mathrm{~cm}$ and served as the model for future altimeter designs, including the U.S. Navy Geosat altimeter (MacArthur and others, 1987) and the European Space Agency ERS-1 altimeter (Somma and others, 1981).

Although the purpose of these space-borne altimeters was for oceanographic studies, satellite orbits to latitudes of $\pm 72.1^{\circ}$ have covered major parts of the Greenland and Antarctic ice sheets. Robin (1966) first proposed the use of satellite altimeters for surveying ice-sheet topography. Since then, data sets from the Geos-3, Seasat and Geosat satellites have been used to produce surface-elevation maps of the Greenland and Antarctic ice sheets with a $2 \mathrm{~m}$ accuracy (Brooks and others, 1978; Zwally and others, 1983; Bindschadler and others, 1989). Space-borne altimeters provide the only proven means for measuring surface elevations with the precision and spatial coverage required for meaningful ice-sheet studies (Thomas, 1991). In 1975, Zwally (Nye, 1975) first proposed that repeated altimeter mapping of surface elevation could be used to 
detect changes in the mass balance of the ice sheets. Significant changes in the volume of the polar ice sheets are directly related to global sea levels and provide an indication of climatic variations. Recently, Zwally and others (1989) measured an average increase in the southern Greenland ice sheet of $23 \mathrm{~cm} y e a r^{-1}$ using Seasat and Geosat altimeter data. Zwally (1989) suggested an increase in precipitation rates caused by a warmer polar climate as a possible cause of the mass imbalance.

Although the primary glaciological application of satellite altimetry is the measurement of surface elevation, the shape of altimeter-return wave forms from the ice sheet is influenced by volume-scattering (Ridley and Partington, 1988; Davis and Moore, 1993). The presence of sub-surface volume-scattering suggests that important geophysical information concerning the near-surface properties of the ice sheet may be derived from the wave-form shape. Based upon a qualitative analysis of averaged return wave forms, Partington and others (1989) showed that the shape of altimeter wave forms from Greenland corresponded to surface-scattering in the low latitudes and volume-scattering in the higher latitudes. They observed only subtle variations in the shape of averaged altimeter wave forms from the Antarctic plateau regions, which were dominated by volume-scattering. By approximating the altimeter's antenna pattern and pulse shape with Gaussian functions, Davis and Moore (1993) derived a closed-form analytical solution for the received power due to volume-scattering. Because an analytical solution is obtained, the model is combined with the Brown surface-scattering model and used as the basis for an algorithm capable of retracking individual altimeter wave forms (Davis, in press). The term "individual wave forms" refers to wave forms telemetered from the satellite at a rate of $10 \mathrm{~s}^{-1}$.

In this paper we fit the combined surface-/volumescattering model to individual altimeter return wave forms, rather than averaged altimeter wave forms as in Partington and others (1989). Using this method, we obtain quantitative estimates of the geographic and seasonal variations in the near-surface properties of the ice sheet. Specifically, the extinction coefficient of snow is found to vary with elevation and latitude over the Greenland and Antarctic ice sheets. Other model parameters such as surface roughness, volume coefficient and wave-form amplitude are also investigated. This technique has important applications for investigating temporal changes in the surface conditions of the ice sheets.

\section{RETRACKING ALGORITHM}

A brief summary of the algorithm used to fit individual altimeter wave forms for this analysis is provided here, while a detailed description has been given by Davis (in press). To develop an algorithm capable of retracking individual return wave forms, the combined surface- and volume-scattering model (Davis and Moore, 1993) is modified to fit telemetered wave-form data. Samples from each altimeter wave form are stored in 60 equally spaced range bins. The modified form of the combined model required to fit individual altimeter wave forms is

$$
\mathrm{SV}(n)=\mathrm{DC}+\frac{\mathrm{A}_{\mathrm{m}}}{\mathrm{S} 2}\left\{\mathrm{~S}(\mathrm{n})+\frac{\mathrm{K}}{\mathrm{S} 1} \mathrm{~V}(n)\right\} .
$$

The surface-scattering model, $\mathrm{S}(n)$, is given by

$$
\begin{aligned}
\mathrm{S}(n)= & \frac{1}{2}\left[1+\operatorname{erf}\left(\frac{g_{2 \mathrm{~s}}\left(n-n^{\prime}\right)}{\sqrt{2} \sigma_{\mathrm{c}}}\right)\right] \text { for } n<n^{\prime} \\
\mathrm{S}(n)= & \frac{1}{2} \exp \left[\frac{-4 c}{\gamma h} g_{2 \mathrm{~s}}\left(n-n^{\prime}\right)\right] \\
& \cdot\left[1+\operatorname{erf}\left(\frac{g_{2 \mathrm{~s}}\left(n-n^{\prime}\right)}{\sqrt{2} \sigma_{\mathrm{c}}}\right)\right] \text { for } n \geq n^{\prime}
\end{aligned}
$$

where $n$ is the range gate number $(0-59), g_{2 s}$ is a constant that converts from gate number to time (range), and $n^{\prime}$ is the gate number corresponding to the mean surface elevation. Similarly, the volume-scattering model, V $(n)$, is given by

$$
\begin{aligned}
& \mathrm{V}(n)=\exp \left(\frac{\beta_{\tau}{ }^{2}}{t_{0}{ }^{2} \beta^{4}}-\frac{2 g_{2 \mathrm{~s}}\left(n-n^{\prime}\right)}{t_{0} \beta^{2}}\right) \\
& -\exp \left(\beta_{\tau}{ }^{2} k_{\mathrm{e}}{ }^{2} c_{\mathrm{s}}{ }^{2}-2 k_{\mathrm{e}} c_{\mathrm{s}} g_{2 \mathrm{~s}}\left(n-n^{\prime}\right)\right),
\end{aligned}
$$

which is valid for $n \geq n^{\prime}$. The parameter DC in Equation (1) is a bias that is present in the return wave forms due to amplification of thermal noise in the altimeter. The parameter $A_{m}$ is the maximum amplitude of the modeled wave form and has dimensions of counts. Internal satellite calibration relates counts to the input power levels at the altimeter's $A / D$ converter. The constants $\mathrm{S} 1$ and $\mathrm{S} 2$ are normalizing factors that ensure the quantities $\mathrm{V}(n)$ and $\{\mathrm{S}(n)+\mathrm{V}(n)\}$ range from 0 to 1 . The $\mathrm{S} 1$ and $\mathrm{S} 2$ constants are required so that $\mathrm{K}$ represents the correct proportion of volume-scattering and $\mathrm{A}_{\mathrm{m}}$ represents the true wave-form amplitude. The six parameters required uniquely to specify a modeled altimeter wave form are summarized in Table 1.

Because the combined model is non-linear, there is no straighforward way optimally to fit the model to the return wave forms and extract the six parameters. This is further complicated due to the "noisy" nature of the individual wave forms, particularly in the plateau region following the initial rise of the leading edge. Both the

Table 1. Model parameters

Parameter Description Units

$\begin{array}{llc}\mathrm{DC} & \text { Altimeter DC bias } & \text { Counts } \\ \sigma_{\mathrm{s}} & \text { r.m.s. surface roughness } & \mathrm{m} \\ n^{\prime} & \text { Mean surface location } & \text { Gate \# } \\ \mathrm{A}_{\mathrm{m}} & \begin{array}{l}\text { Maximum wave-form } \\ \text { amplitude }\end{array} & \text { Counts } \\ \mathrm{K} & \begin{array}{l}\text { Volume-scattering } \\ \text { coefficient } \\ \text { Extinction coefficient } \\ \text { of snow }\end{array} & - \\ k_{\mathrm{e}} & \mathrm{m}^{-1} \\ & & \end{array}$


surface- and volume-scattering models describe the mean received power, whereas return wave forms fluctuate about the mean because of fading, variations in surface geometry and inhomogeneities.

Ideally, one should use some type of least-squares fitting procedure to extract the appropriate model parameters. However, in practice there are a limited number of function types where the normal equations are directly solvable in an ordinary least-squares sense. The non-linear model produces an intractable set of normal equations and an iterative scheme must be employed to fit the model to the wave-form data.

The approach taken here is similar to those used earlier to extract ocean significant wave heights from Geos-3 altimeter data (Hayne, 1977, 1981) and to obtain ice-sheet elevations (Zwally and others, 1990). The procedure is summarized by the following steps:

(a) Make an initial estimate for the unknown model parameters.

(b) Perform a first-order Taylor series expansion around the initial-estimate values.

(c) Find the least-squares solution for the corrections to the initial-estimate values.

(d) Use the revised parameter values for a new initial estimate.

(e) Repeat steps (b), (c) and (d) until some exit criterion is satisfied.

For our particular application, we have $j=1$ to 6 model parameters

$$
\mathrm{MP}_{j}=\left\{\mathrm{MP}_{1}, \mathrm{MP}_{2}, \cdots, \mathrm{MP}_{6}\right\}
$$

and $n=0$ to 59 model wave-form values

$$
\mathrm{WV}_{n}=\mathrm{SV}\left(n, \mathrm{MP}_{j}\right)
$$

that must be fitted to the wave-form data values, $Y_{n}$. Define $\mathrm{MP}_{j_{0}}$ as a set of initial guesses for the six model parameters, and $\mathrm{WV}_{n_{0}}$ as the corresponding model function values. Also define

and

$$
\mathrm{PD}_{n j}=\frac{\partial}{\partial \mathrm{MP}_{j}} \mathrm{SV}\left(n, \mathrm{MP}_{j_{0}}\right)
$$

$$
\delta_{j}=\mathrm{MP}_{j}^{+}-\mathrm{MP}_{j_{0}}
$$

where $\mathrm{MP}_{j}{ }^{+}$are the new model-parameter estimates after one iteration. The new parameter estimates are found by solving the matrix equation

$$
\Delta=\mathbf{A}^{-1} \mathbf{B}
$$

where

$$
\begin{gathered}
\Delta=\left[\begin{array}{c}
\delta_{1} \\
\delta_{2} \\
\vdots \\
\delta_{6}
\end{array}\right] \\
\mathbf{B}=\left[\begin{array}{c}
\sum w_{n} \mathrm{PD}_{n_{1}}\left(Y_{n}-\mathrm{WV}_{n_{0}}\right) \\
\sum w_{n} \mathrm{PD}_{n_{2}}\left(Y_{n}-\mathrm{WV}_{n_{0}}\right) \\
\vdots \\
\sum w_{n} \mathrm{PD}_{n_{6}}\left(Y_{n}-\mathrm{WV}_{n_{0}}\right)
\end{array}\right]
\end{gathered}
$$

and

$$
\mathbf{A}=\left[\begin{array}{ccc}
\sum w_{n} \mathrm{PD}_{n_{1}} \mathrm{PD}_{n_{1}} \cdots & \sum w_{n} \mathrm{PD}_{n_{1}} \mathrm{PD}_{n_{6}} \\
\sum w_{n} \mathrm{PD}_{n_{2}} \mathrm{PD}_{n_{1}} \cdots & \sum w_{n} \mathrm{PD}_{n_{2}} \mathrm{PD}_{n_{6}} \\
\vdots & \ddots & \vdots \\
\sum w_{n} \mathrm{PD}_{n_{6}} \mathrm{PD}_{n_{1}} \cdots & \sum w_{n} \mathrm{PD}_{n_{6}} \mathrm{PD}_{n_{6}}
\end{array}\right]
$$

All the indicated summations are from $n=0$ to 59 , and $w_{n}$ is a set of weights assigned to the wave-form data values, $Y_{n}$. Once the matrix equation in (8) is solved, new model-parameter estimates are obtained from Equation (7). The new parameter estimates are then substituted for the initial estimates and the process is repeated until a convergence criterion is satisfied.

To generate initial parameter estimates, a smoothing filter is applied to the altimeter return wave form. This is done to minimize the effects of noisy fluctuations present in the individual wave forms on the initial parameter estimates. The initial estimates are formed from the slope and amplitude information in the smoothed wave form. Generally speaking, large leading-edge slopes generate surface-scattering parameter estimates, while small leading edge slopes generate volume-scattering parameter estimates. The amplitude information is used to develop estimates for the $\mathrm{DC}$ and $\mathrm{A}_{\mathrm{m}}$ parameters.

The sample weights are generated using the slope information from the smoothed wave form to determine the location of the wave-form's leading edge. Using this location, the wave-form samples occurring before the leading edge are assigned smaller weights than those occurring beyond the leading edge. This, in effect, assigns a greater importance to the samples that comprise the return wave-form power and lessens the effect of the samples that represent the pre-leading edge DC bias.

After corrected parameter estimates are obtained by solving Equation (8), several exit criteria are checked to determine whether further iterations are required. The first exit criterion is based upon the absolute change in all six model parameters between subsequent iterations. If all six model parameters have not changed by an absolute difference specified for each individual parameter, the algorithm loop terminates. The second-exit criterion is based upon the relative change in the mean-squared error

$$
\mathrm{MSE}=\frac{1}{60} \sum_{n=0}^{59}\left(\mathrm{WV}_{n}-Y_{n}\right)^{2}
$$

If the relative change in the MSE is less than a specified tolerance from one iteration to the next, the model fit is no longer improving and the algorithm loop terminates. The final-exit criterion limits the number of iterations. Because the model is non-linear, the algorithm can diverge. Hence, a maximum of 15 iterations is set to avoid an infinite looping situation. The parameter estimates are retained if the algorithm exits after fewer than 15 iterations; they are discarded if the other criteria fail in 15 iterations.

A few examples of the retracking algorithm-model fits to individual altimeter wave forms are shown in Figure 1. As one can see, the model accurately fits a variety of surface- and volume-scattering wave forms. This algorithm was used to retrack over 400000 altimeter wave forms from the Greenland and Antarctic ice sheets. The 

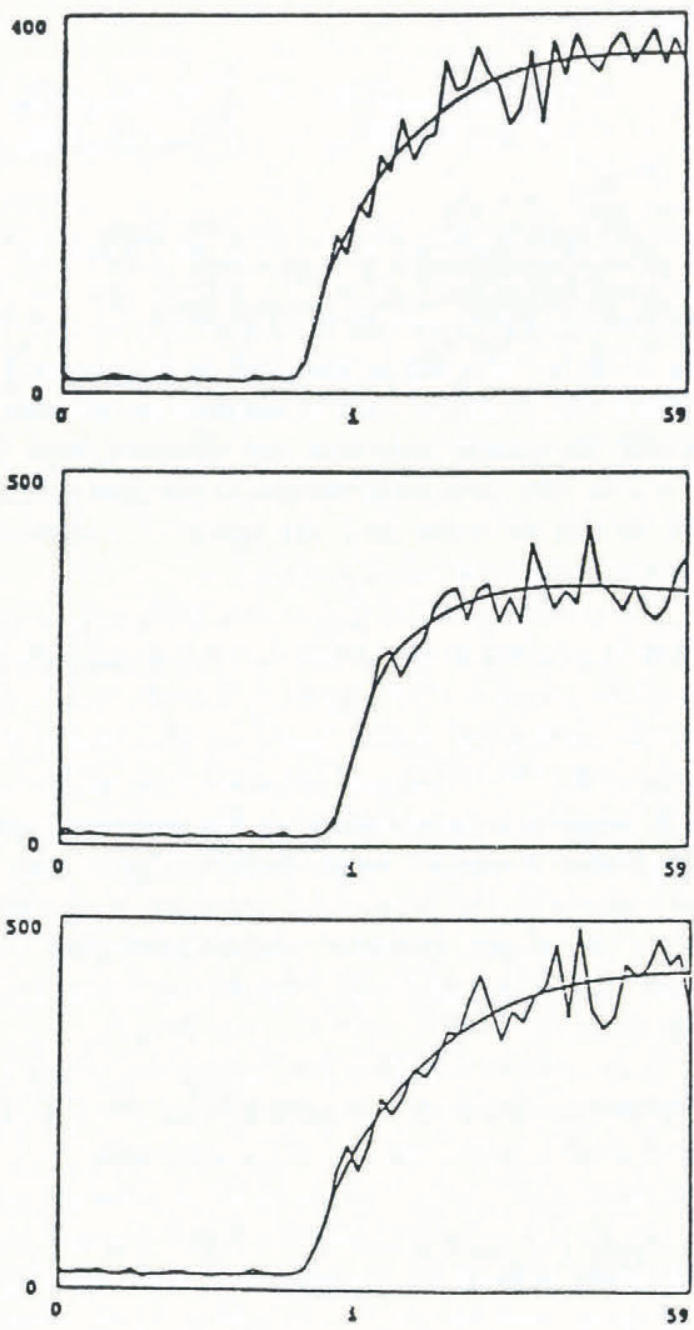
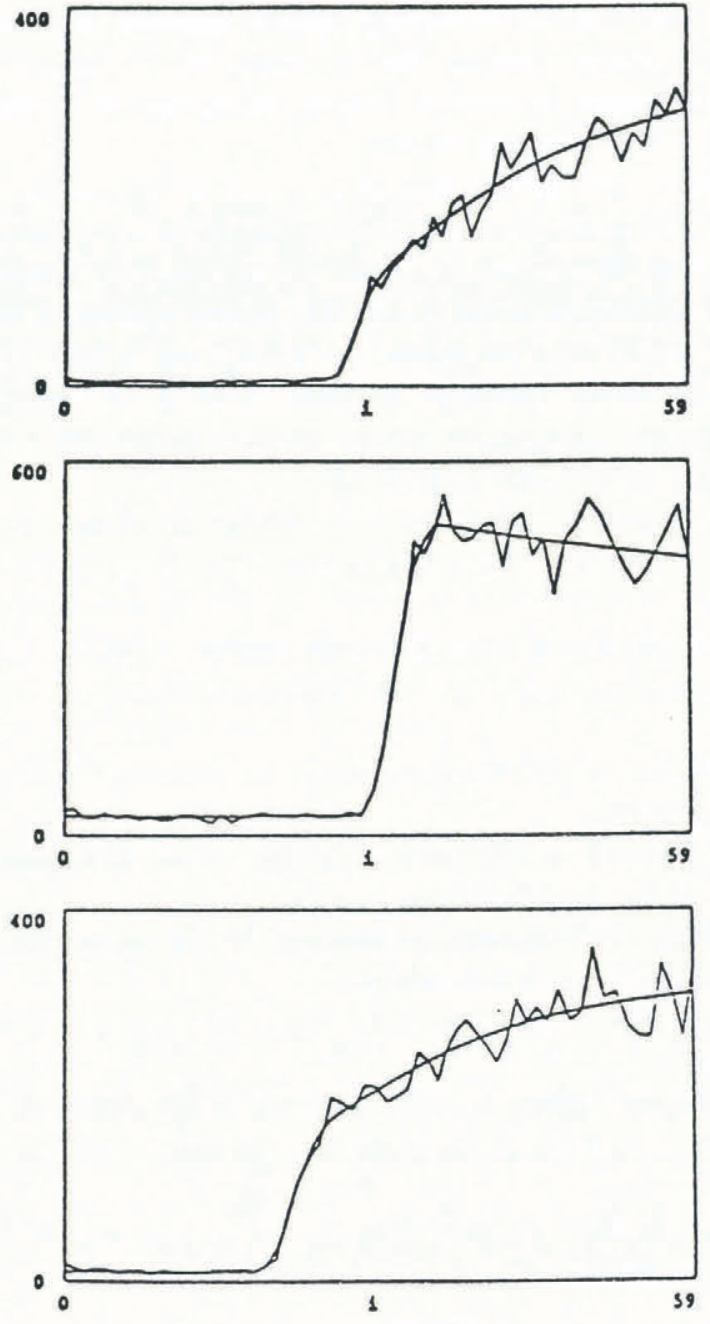

Fig. 1. Retracking algorithm model fits to individual altimeter wave forms.

maximum number of iterations was exceeded for less than $2 \%$ of the wave-form data. The average number of iterations for algorithm convergence was eight to ten, which corresponds to approximately $0.5 \mathrm{~s} /$ wave form on a $25 \mathrm{MHz}, 80486$-based personal computer. The short fitting time demonstrates that this retracking algorithm can be applied to large numbers of altimeter wave forms without dedication of large computing resources.

\section{DATA SETS AND PROCESSING}

Two regions from the Greenland and Antarctic ice sheets are selected to cover a wide range of latitude and elevation. A summary of the data regions is shown in Table 2. The Greenland data set is in a rectangular area that is $1^{\circ}$ wide and covers $63^{\circ}$ to $72^{\circ} \mathrm{N}$. The Antarctic data set is in a region bounded by $71.5^{\circ}$ to $72.1^{\circ} \mathrm{S}$ and $80^{\circ}$ to $100^{\circ} \mathrm{E}$. Elevation profiles for the selected areas are shown in Figure 2. The Greenland profile begins at an elevation of $2700 \mathrm{~m}$ on the southern dome, drops to an elevation of $2500 \mathrm{~m}$ at $65^{\circ} \mathrm{N}$ and then increases to a maximum elevation of $3050 \mathrm{~m}$ at $72^{\circ} \mathrm{N}$. The Antarctic profile begins at an elevation of $2550 \mathrm{~m}$ at $80^{\circ} \mathrm{E}$, increases to an elevation of $3150 \mathrm{~m}$ at the ice divide $\left(94^{\circ} \mathrm{E}\right)$ and then decreases to an elevation of $3000 \mathrm{~m}$ at $100^{\circ} \mathrm{E}$.

Near the periphery of the ice sheet, large surface slopes cause the altimeter wave forms to be severely attenuated. The attenuation is caused by a reduction in antenna gain that occurs for areas located near the edge of the altimeter beam. Both the surface- and volume-scattering models are derived assuming a horizontal surface. Thus, for this analysis, we selected regions in Greenland and Antarctica containing local surface slopes less than $0.4^{\circ}$.

Geosat altimeter wave forms from the selected regions are from the summer and winter seasons of 1986 and 1987 (Table 2). The Greenland data set from $63-72^{\circ} \mathrm{N}$ is subdivided into 18 smaller regions that are $1^{\circ} \times 0.5^{\circ}$ (long. $\times$ lat.), and the Antarctic data set from $80-100^{\circ} \mathrm{E}$ is subdivided into 20 smaller regions that are $1^{\circ} \times 0.6^{\circ}$ (long. $\times$ lat.). Because the density of the satellite ground tracks increases with latitude, the number of wave forms present in each subdivided region from the Greenland data set increases from approximately 100 at $63^{\circ} \mathrm{N}$ to 2400 at $72^{\circ} \mathrm{N}$. Since the Antarctic data set is bounded by the maximum latitude of the satellite, approximately 2500 wave forms are present in each subdivided region. These numbers vary slightly from season to season and year to year.

In their analysis of altimeter wave forms from the ice sheets, Partington and others (1989) averaged thousands of return wave forms together and then fitted their model to the averaged wave form. They used this approach because most of the individual wave forms from Seasat 
Greenland 1986, 1987

Jan-Feb

Jul-Aug

Antarctica $\quad 1986,1987$

Jul-Aug

Jan-Feb $63^{\circ} \mathrm{N} 314^{\circ} \mathrm{E}-63^{\circ} \mathrm{N} 315^{\circ} \mathrm{E}^{*}$

$72^{\circ} \mathrm{N} 319^{\circ} \mathrm{E}-72^{\circ} \mathrm{N} 320^{\circ} \mathrm{E}^{*}$

$71.5-72.1^{\circ} \mathrm{S}, 80-100^{\circ} \mathrm{E}^{\dagger}$

* Coordinates that correspond to the corners of a rectangular area that is longitudinally one deg wide.

${ }^{\dagger}$ Arc-like region bounded in latitude and longitude.

and Geosat did not conform to their model's shape (p. 269). The averaging was performed to get rid of return-power fluctuations caused by fading and variations in surface geometry. However, they noted (p. 271) that the wave-form averaging caused their model's "inflection points", which represent the transition point from the surface-scattering to the volume-scattering part of the wave form, to be absent from the averaged wave form. Presumably, the inflection point is lost in the averaged
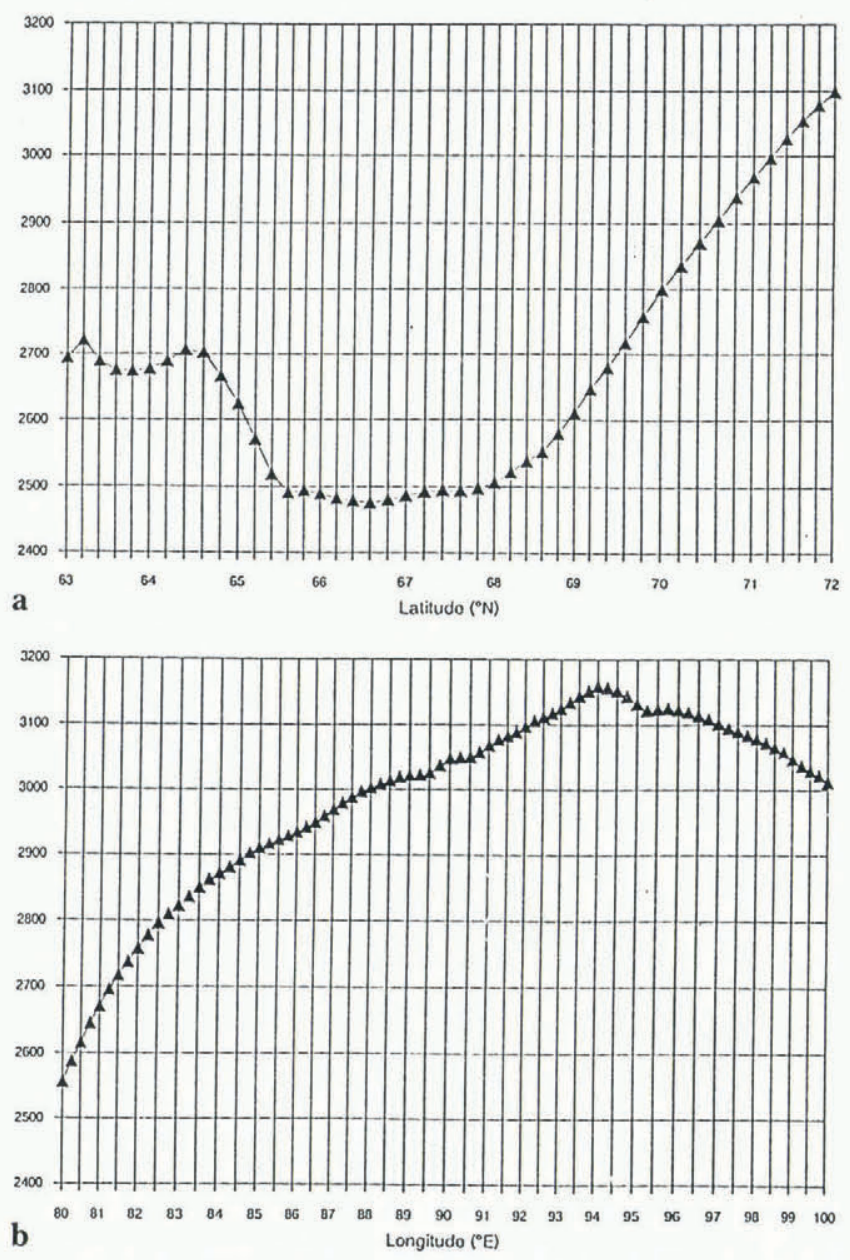

Fig. 2. Elevation profiles for data regions. (a) Central part of the Greenland ice sheet from $63^{\circ}$ to $72^{\circ} \mathcal{N}$. (b) Wilkes Land in East Antarctica from $80^{\circ}$ to $100^{\circ} \mathrm{E}$ at $72^{\circ} \mathrm{S}$. wave form, because the relative contribution of surfaceand volume-scattering varies sufficiently over the region so that the position of the inflection point on the individual wave forms is not constant.

In our approach, we fit the combined model (Davis and Moore, 1993) to individual altimeter-return wave forms in the subdivided regions. As seen in Figure 1, the combined model characterizes the relative contribution of surface- and volume-scattering for the individual altimeter wave forms. After fitting the individual wave forms, we average the model parameters from the individual wave-form fits together for each subdivided region. Then, we examine the seasonal and geographic variations in the sample mean of the particular model parameter. By fitting large numbers of individual wave forms, sufficient samples of the model parameters are obtained to characterize seasonal and geographic differences in the surface properties of the ice sheet. For analysis of geographic variations, model-parameter averages from approximately 100 individual wave forms are sufficient. For analysis of the smaller seasonal variations, modelparameter averages from approximately 1000 individual wave forms are required.

\section{RESULTS AND DISCUSSION}

\section{Greenland data set}

The extinction coefficient of snow obtained by fitting the combined model to Geosat wave forms is shown in Figure 3 for the summer and winter seasons of 1986 and 1987. The data point at each latitude represents the sample mean for the region extending from the given latitude to a latitude $\frac{1}{2}^{\circ}$ higher, i.e. the data point at $71.5^{\circ} \mathrm{N}$ corresponds to the region $71.5-72.0^{\circ} \mathrm{N}$. The overall variation with latitude is the same for both years. The extinction coefficient, $k_{\mathrm{e}}$, has a maximum value of approximately $0.5 \mathrm{~m}^{-1}$ at $65-66^{\circ} \mathrm{N}$ and steadily decreases to a minimum value of approximately $0.15 \mathrm{~m}^{-1}$ at $71-72^{\circ} \mathrm{N}$. Note that the maximum value of $k_{\mathrm{e}}$ occurs where the surface elevation is a minimum (Fig. 2a) as discussed later. The values of $k_{\mathrm{e}}$ south of $65^{\circ} \mathrm{N}$ are smaller than $0.5 \mathrm{~m}^{-1}$ and this is probably caused by the higher surface elevations of the southern Greenland dome (Fig. $2 a)$. Another cause may be the small number $(\approx 100)$ of 

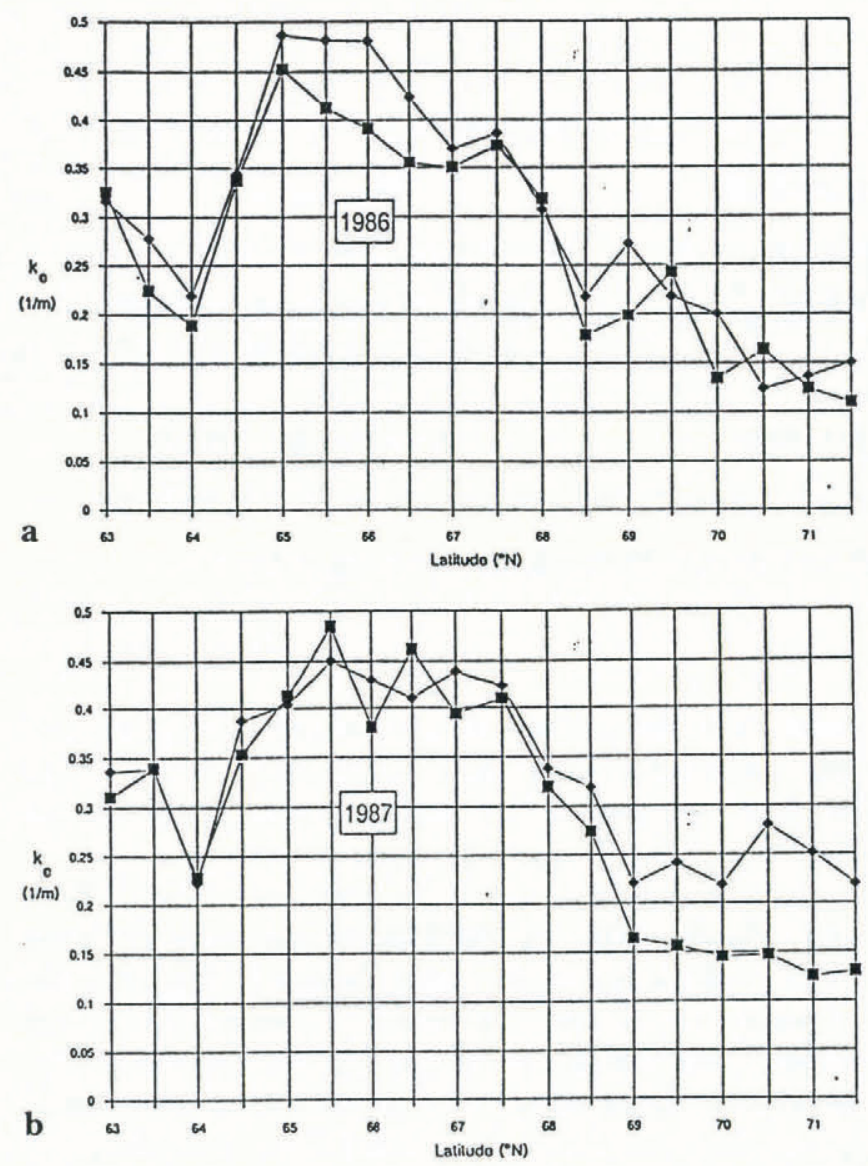

Fig. 3. Extinction coefficient vs latitude for the summer (diamonds) and winter (boxes) seasons. (a) 1986 data set. (b) 1987 data set.

altimeter wave forms present in these subdivided regions of the data set, since this results in less accurate estimates of the extinction coefficient than at the higher latitudes. However, since the smaller extinction-coefficient values occur in both seasons and both years of the data set, the higher surface elevation is the more likely cause. To examine the summer-to-winter differences in the extinction coefficient, a Student's $t$-test is used to determine the significance of the sample-mean differences for each region. The extinction-coefficient differences for the latitudes $69-72^{\circ} \mathrm{N}$ in the 1987 data set are significant at the $1 \%$ level. Most of the other regions had significance

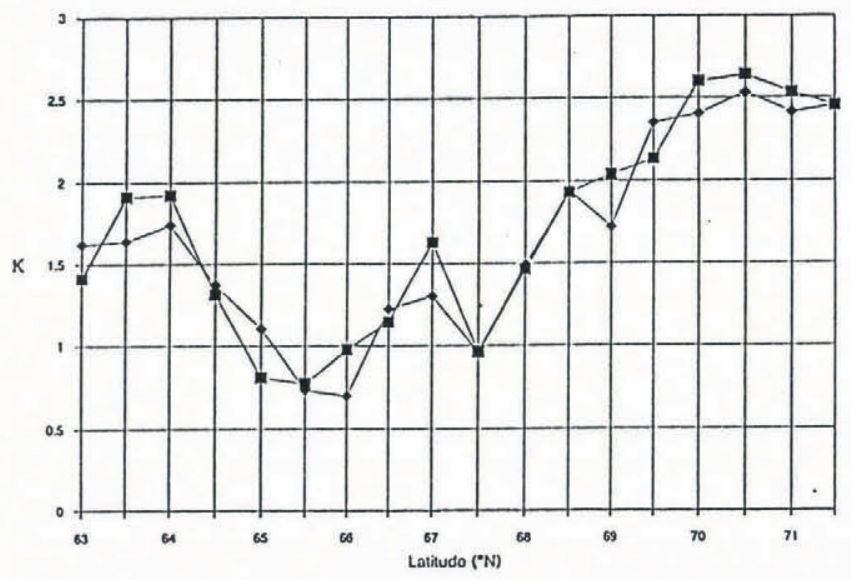

Fig. 4. Volume coefficient vs latitude for the summer (diamonds) and winter (boxes) seasons of 1986. levels greater than $10 \%$, indicating that these seasonal differences are not significant.

Figure 4 shows a plot of the volume coefficient, $K$, for the 1986 data set. The volume coefficient has a minimum value of approximately 0.75 at $65^{\circ} \mathrm{N}$ and steadily increases with latitude and elevation to a value of approximately 2.5 at $71.5^{\circ} \mathrm{N}$. Note also that the volume-coefficient values in the higher elevations of the southern dome $\left(63-65^{\circ} \mathrm{N}\right)$ are slightly larger than the minimum value of 0.75 . The same trend in the volumecoefficient plot is also present in the 1987 data set.

For an extinction coefficient of snow independent of depth, the depth of penetration is defined by

$$
d_{\mathrm{p}}=\frac{1}{k_{\mathrm{e}}}
$$

Comparing the volume- and extinction-coefficient plots for the 1986 data set, we see that large values of $k_{\mathrm{e}}$ correspond to small values of $K$. For the lower elevations, the depth of penetration is on the order of a few meters. Thus, surface-scattering dominates the shape of the return wave forms, resulting in small volume-coefficient values. As depth of penetration increases with elevation, volumescattering contributes more to the received power, so that larger volume coefficients are observed. Small-scale variations in the extinction coefficient and volume coefficient may be related to local variations in surface roughness, surface crusts and wind intensity. However, the dominant regional trend in the extinction and volume coefficients over the Greenland ice sheet is strongly related to surface elevation and latitude. Surfacescattering dominates in the lower elevations, while the amount of sub-surface volume-scattering increases as elevation and latitude increase.

The dependence of the extinction and volume coefficients on surface elevation and latitude is an indication of variations in the physical properties of the ice sheet. Characteristics like accumulation rates, mean annual temperature and amount of surface melting all affect the densities and grain-sizes of the near-surface snow. Snow that is subjected to alternate melting and freezing has enhanced grain-sizes, ice lenses and hard surface crusts. Surface-scattering increases substantially when surface crusts are present, while larger grain-sizes and ice lenses increase the extinction coefficient of snow.

The map produced by Benson (1962) of the diagenetic zones for the Greenland ice sheet indicates that the drysnow zone extends from $70^{\circ}$ to $72^{\circ} \mathrm{N}$ for the region studied here. The percolation zone, where some summer melting occurs, extends from $63^{\circ}$ to $70^{\circ} \mathrm{N}$. Using $18 \mathrm{GHz}$ brightness-temperature data from the Scanning Multichannel Microwave Radiometer (SMMR), we determine the average number of melt dyear ${ }^{-1}$ for the Greenland data set. When surface melting occurs, the observed brightness temperature increases dramatically (Zwally and Gloerson, 1977). The average brightness temperature for a single point in each subdivided region is found for the 8 year period $1979-87$. Then the number of days the brightness temperature exceeds the 8 year average by $30 \mathrm{~K}$ is determined. Since the SMMR instrument only produced brightness-temperature data every other day, the total number of melt days is multiplied by a factor of 2. A similar method was used previously by Zwally and 
Fiegles (paper in preparation) to measure the number of melt days on the Antarctic continent.

The average number of melt $d$ year ${ }^{-1}$ for the period $1979-87$ is shown in Figure 5. For $63.0-68.5^{\circ} \mathrm{N}$, the

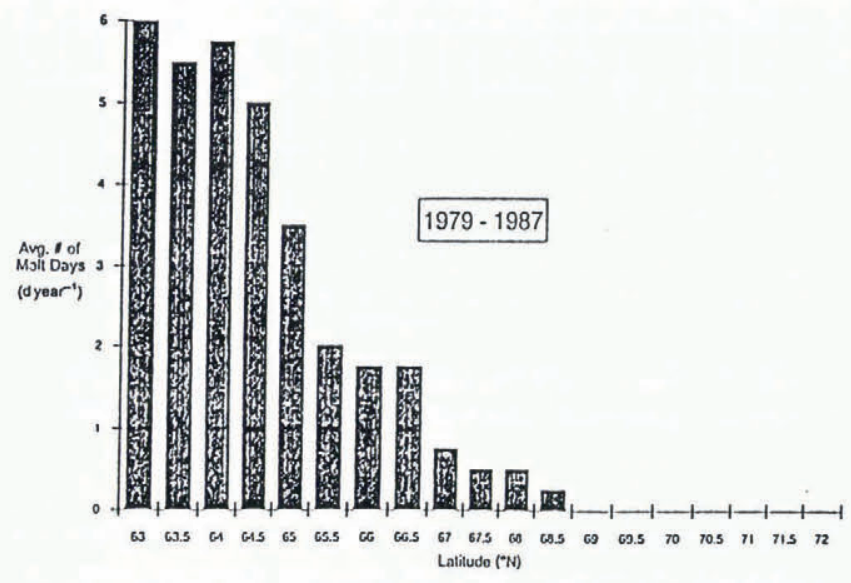

Fig. 5. Average number of melt d year ${ }^{-1}$ vs latitude for the period $1979-87$.

average number of melt days decreases from 6 to $0.25 \mathrm{~d}_{\text {year }}{ }^{-1}$, while no melt events are observed for latitudes beyond $68.5^{\circ} \mathrm{N}$. It is clear that the regional trend in the extinction and volume coefficients for the Greenland data set is related to the amount of surface melting on the ice sheet. The high extinction-coefficient and low volume-coefficient values occur at the lower latitudes where a large number of melt days occur. As the amount of surface melting decreases with latitude, the extinction coefficient decreases and the volume coefficient increases. In the dry-snow zone (lat. $>68.5^{\circ} \mathrm{N}$ ), the extinction coefficient reaches its minimum and the volume coefficient reaches its maximum, reflecting the increase in volume-scattered power in the altimeter return wave forms. The penetration depth is $5-7 \mathrm{~m}$ for this region at the altimeter frequency of $13.5 \mathrm{GHz}$.

\section{Antarctic data set}

A plot of the extinction coefficient vs longitude for the summer and winter seasons of 1986 is shown in Figure 6. The data point at each latitude represents the sample

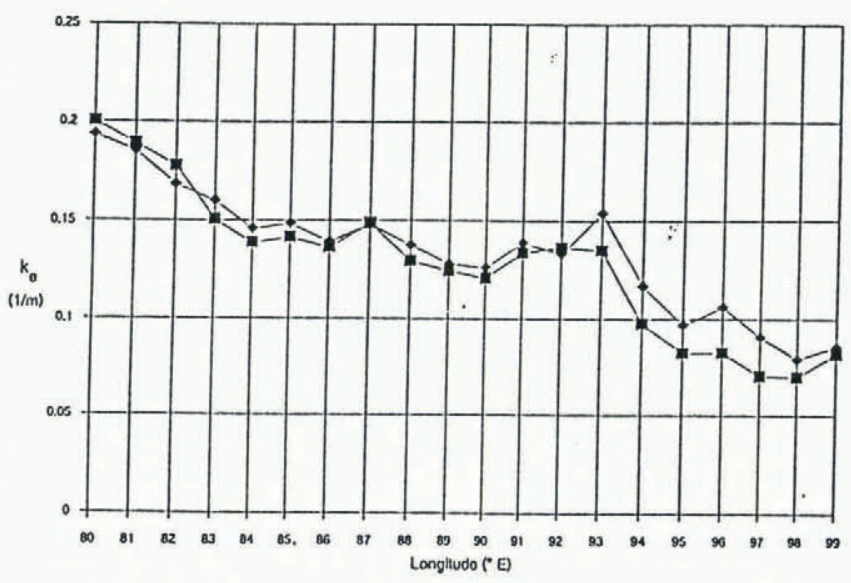

Fig. 6. Extinction coefficient vs longitude for the summer (diamonds) and winter (boxes) seasons of 1986. mean for the region extending from the given longitude to a longitude $1^{\circ}$ higher, i.e. the data point at $89^{\circ} \mathrm{E}$ corresponds to the region $89-90^{\circ} \mathrm{E}$. The extinction coefficient decreases from a maximum value of $0.2 \mathrm{~m}^{-1}$ at $80^{\circ} \mathrm{E}$ to a minimum value of approximately $0.08 \mathrm{~m}^{-1}$ at $99^{\circ} \mathrm{E}$. This corresponds to penetration depths that range from 5.0 to $12.5 \mathrm{~m}$. The 1987 data show the same extinction-coefficient variation with longitude. The maximum value of $k_{\mathrm{e}} \approx 0.2 \mathrm{~m}^{-1}$ is much smaller than the maximum value in the Greenland data set of $k_{\mathrm{e}} \approx 0.5 \mathrm{~m}^{-1}$. Unlike the Greenland ice sheet, most of the Antarctic ice sheet is classified as a dry-snow zone. Enhanced snow grain-sizes, resulting from surface melting, produce larger extinction-coefficient values for the Greenland data than those of the Antarctic data. The decrease in $k_{\mathrm{e}}$ from $80^{\circ}$ to $93^{\circ} \mathrm{E}$ is strongly related to the increase in elevation from 2550 to $3125 \mathrm{~m}$ (Fig. 2b). Beyond the ice divide at $94^{\circ} \mathrm{E}$, the extinction coefficient experiences a sharp decrease even though the elevation drops slightly from 3150 to $3000 \mathrm{~m}$. This decrease is

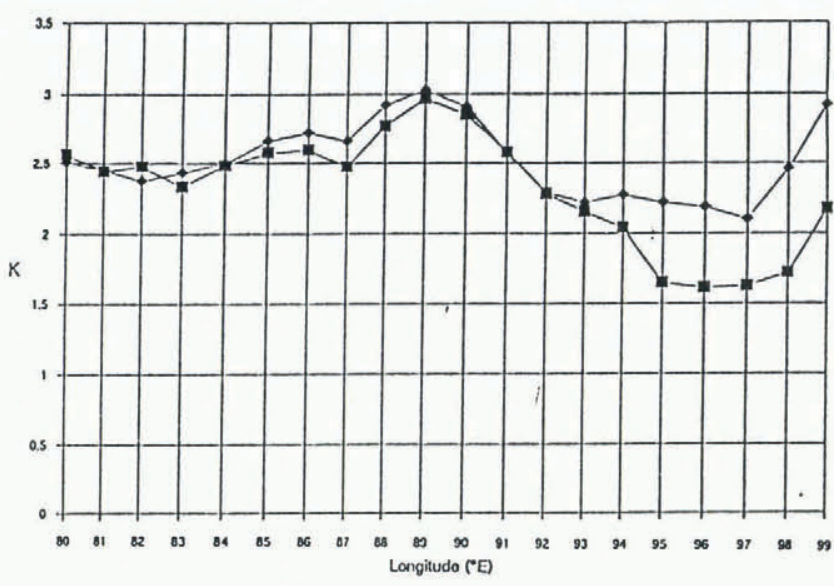

Fig. 7. Volume coefficient vs longitude for the summer (diamonds) and winter (boxes) seasons of 1986.

probably related to a marked difference in the physical properties of the snow on either side of the ice divide. In addition to surface elevation, another factor that affects surface temperatures is the distance from the coastline. Colder temperatures occur as the distance from the open ocean increases. At $72^{\circ} \mathrm{S}$, the distance from the Antarctic coastline increases from approximately 350 to $720 \mathrm{~km}$ for $80-100^{\circ} \mathrm{E}$.

Figure 7 shows a plot of the volume coefficient vs longitude for the summer and winter seasons of 1986 . Most of the volume-coefficient values are greater than 2.0, indicating that the return wave forms are dominated by volume-scattering. For the Greenland data set, the volume-coefficient values only exceeded 2.0 for 70 $72^{\circ} \mathrm{N}$, where surface elevations approach the maximum (Fig. 2a) and no surface melting occurs (Fig. 5). There is a large seasonal difference in the volume-coefficient values for $95-100^{\circ} \mathrm{E}$. The summer values of $\mathrm{K}$ are approximately $25 \%$ higher than the winter values. Using a Student's $t$-test, the difference in the sample means is found to be significant at the $1 \%$ level. The same regional trends in the volume coefficient were observed in the 1987 
data set, except that the seasonal differences from 95$100^{\circ} \mathrm{E}$ were not present. The seasonal difference in $\mathrm{K}$ (east of $95^{\circ} \mathrm{E}$ ) in the 1986 data set indicates a change in the amount of surface-scattering, possibly due to the formation of a surface crust.

For the Greenland data, a decrease in the extinction coefficient with increasing elevation is accompanied by an increase in the volume coefficient. For the Antarctic data set, there is no clear relationship between the trends in the extinction and volume coefficients. For the region 80 $89^{\circ} \mathrm{E}$, the decrease in extinction coefficient is accompanied by an increase in the volume coefficient. However, for the region $89-93^{\circ} \mathrm{E}$, the extinction coefficient remains nearly constant while the volume coefficient decreases substantially. Large variations in both the extinction and volume coefficients of the Greenland data probably occur because of larger grain-sizes caused by surface melting. Even though the surface elevations for both data sets range from approximately 2500 to $3200 \mathrm{~m}$, smaller variations in $k_{\mathrm{e}}$ and $\mathrm{K}$ are present in the Antarctic data because the absence of surface melting causes smaller variations in the grain-size distributions. For the Greenland data, the large-scale trend in $k_{\mathrm{e}}$ and $\mathrm{K}$ is dominated by the amount of surface melting, while small-scale variations may be related to local variations in surface crusts, snow densities, etc. For the Antarctic data, no large-scale trend appears in the volume coefficient and the observed variations are probably related to regional differences in surface crusts, accumulation rates and wind intensity.

The large-scale trend in the extinction coefficient relates strongly to surface elevation and the distance from the coastline. These characteristics are proxies for physical conditions such as mean annual temperature and accumulation rate. The growth rate of ice crystals in polar firn depends upon the mean annual surface temperature (Gow, 1969, 1971). Regions lower in surface elevation and closer to the coast have warmer surface temperatures. Warmer surface temperatures produce higher recrystallization rates and larger grain-sizes, which increase the extinction coefficient. Thus, regions that have lower surface elevations and are closer to the coast generally have higher extinction coefficients.

Analysis of passive-microwave images from the Antarctic ice sheet showed that brightness-temperature patterns are related to accumulation rates and surface temperature (Chang and others, 1976; Zwally and Gloerson, 1977; Rotman and others, 1982). Theoretical work (Zwally, 1977; Comiso and others, 1982) showed that the microwave emissivity is controled by variations in the density and grain-size of polar firn as a function of depth. As the average grain-size increases, the amount of emitted energy from greater snow depths is reduced, thereby decreasing the observed brightness temperature. Using $18 \mathrm{GHz}$ SMMR brightness-temperature data, the mean brightness temperatures for a single point in each subdivided region of the Antarctic data set are determined for the summer and winter seasons. A plot of the mean brightness temperature vs longitude is shown in Figure 8. For both seasons, the mean brightness temperature increases with longitude, suggesting that the average grain-size is decreasing.

Comparing the brightness-temperature and extinct-

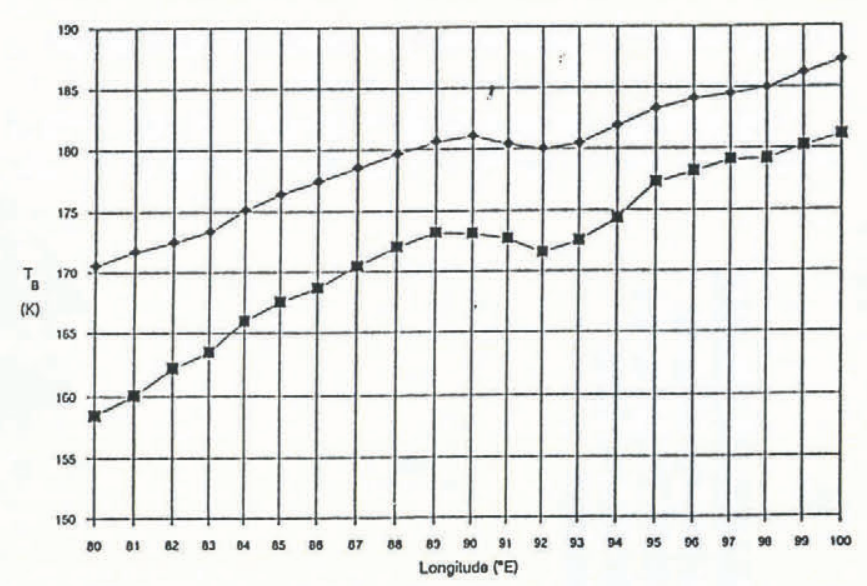

Fig. 8. Mean brightness temperature vs longitude for the summer (diamonds) and winter (boxes) seasons of 1986 .

ion-coefficient plots, we see that as the extinction coefficient decreases the brightness temperature increases. Smaller average grain-sizes decrease the extinction (primarily scattering) coefficient of snow. Thus, emitted energy from greater snow depths increases, thereby increasing the observed brightness temperatures. Note also that, in the region $88-93^{\circ} \mathrm{E}$, the extinction coefficient and mean brightness temperature are nearly constant with longitude for both the summer and winter seasons. This region west of the ice divide may experience a lower accumulation rate, which would cause the average grain-sizes to be slightly larger than the grain-sizes in the adjacent regions. If true, this would explain the interruption of the large-scale variation with longitude in both the extinction-coefficient and brightness-temperature plots. The large-scale variations are probably controled by the grain-size dependence on temperature variations associated with surface elevation and distance from the coastline. The small-scale variations are probably related to local variations in accumulation rate and surface crusts.

By fitting their model to averaged wave forms from the East Antarctic plateau, Partington and others (1989) determined that the extinction coefficient was constant across the region $80-160^{\circ} \mathrm{E}$, and they attributed variations in the averaged wave forms to variations in surface crusts. The results presented here clearly show variations in the extinction coefficient over the East Antarctic ice sheet. These variations are strongly related to characteristics like surface elevation and distance from the coastline. This result is supported by the work that describes the effects of temperature on the growth rate of ice crystals in polar firn and passive-microwave observations of the polar ice sheet. In addition, recent analysis of in situ $10 \mathrm{GHz}$ radar data taken in East Antarctica (Davis and Poznyak, in press) showed that radar energy at this frequency can penetrate many meters beneath the surface of the ice sheet and that the depth of penetration varies with surface elevation and distance from the Antarctic coast. The inability of the Partington and others (1989) approach to determine variations in the extinction coefficient is probably the result of averaging large numbers of individual altimeter wave forms over large areas where the physical characteristics of the ice sheet are not constant. Their approach averages out 
statistical fluctuations in the wave-form shape but it also averages out real changes in the near-surface properties of the ice sheet. Because Partington and others (1989) found the extinction coefficient to be constant across East Antarctica, the accuracy of their estimates of surface roughness and ratio of surface- to volume-scattering may be in doubt for similar reasons.

Another model parameter that may provide important geophysical information about the ice sheets is the wave-form amplitude, $A_{\mathrm{m}}$. The Geosat altimeter used an automatic gain-control (AGC) tracking loop to maintain the total return power at a constant level. The AGC value and the wave-form amplitude are used to determine an absolute amplitude of the return power in $\mathrm{dB}$ using

$$
\text { Abs. Amp. }=\mathrm{AGC}+10 \log A_{m} \text {. }
$$

Figure 9 shows a plot of the absolute amplitude vs longitude for the 1986 summer season of the Antarctic data set. The absolute amplitude decreases from 58 to $51 \mathrm{~dB}$ for $80-99^{\circ} \mathrm{E}$. The amplitude variation is strongly related to the decrease in extinction coefficient (Fig. 6). Since the volume-coefficient values are all larger than 2.0 for this data set, we conclude that the return wave forms are dominated by volume-scattered power. The magnitude of the volume-scattered power is related to the scattering coefficient of snow, $k_{\mathrm{s}}$, which, in turn, is related to the average grain-size of the ice crystals. From the extinction-coefficient and brightness-temperature data presented earlier, we conclude that the average grainsize decreases with increasing surface elevation and distance from the coast for the region studied here. Thus, the volume-scattering coefficient of snow also decreases with surface elevation and distance from the coast, and this accounts for the observed decrease in the magnitude of the volume-scattered power.

Remy and others (1990) recently concluded that variations in the return power over the East Antarctic ice sheet are related to katabatic wind intensity. A basis for the Remy and others' work was that the extinction coefficient estimated by Partington and others (1989) did not vary with surface elevation and that their observed variations in return power did not vary with surface elevation. The results presented here clearly demonstrate that, at least for this part of East Antarctica, the

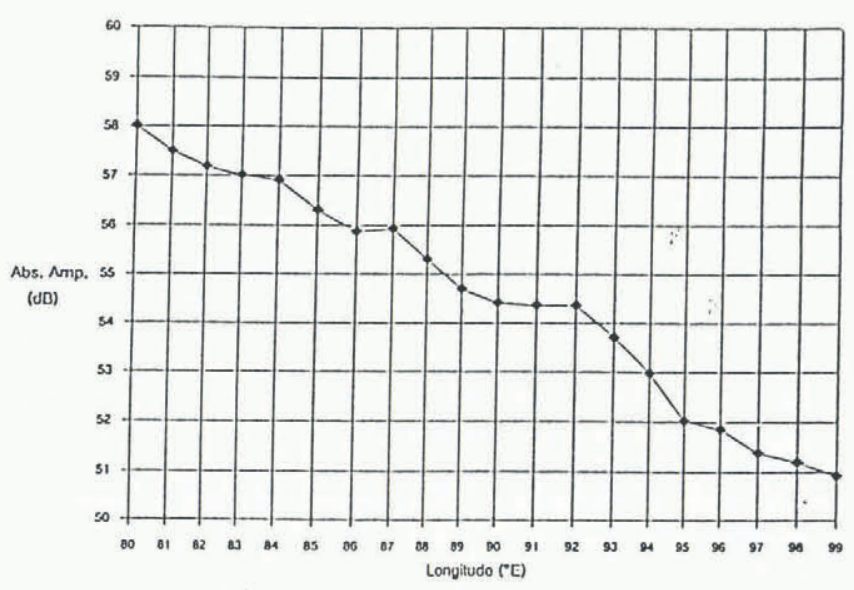

Fig. 9. Absolute amplitude vs longitude for the summer season of 1986 . extinction coefficient and return power do vary with elevation. A possible cause for the discrepancy between this work and that of Remy and others is the number of data points used in each region. Remy and others used an average of 25 data points for regions $20 \times 30 \mathrm{~km}^{2}$, while our work used an average of 2500 data points for regions $30 \times 60 \mathrm{~km}^{2}$. The sample variances associated with the values in Figure 9 range from 4 to $8 \mathrm{~dB}$. This suggests that the small number of data points used by Rerny and others is insufficient to characterize average return-power levels for this region of East Antarctica. This is especially true if the small set of data points was from only one or two satellite tracks in each region. Return-power levels within each satellite track are correlated and could be corrupted by pointing-angle errors.

Another model parameter of interest is the r.m.s. surface roughness, $\sigma_{8}$, which is related to the width of the leading edge of the surface-scattering component in the return wave form. Over the ocean, the width of the leading edge of the return wave form is a measure of the significant wave height, where the leading-edge width increases as the wave height increases. Over the ice sheet the same basic principle still applies. However, a major difference is that the ocean return is surface-scattering only, while the ice-sheet return is a combination of surface- and volume-scattering. The accuracy of surfaceroughness measurements over the ice sheet depends upon the accuracy with which the surface-scattering component can be separated from the volume-scattered component of the return power. The retracking algorithm used by Martin and others (1983) and Zwally and others (1990) for processing Seasat and Geosat data from the ice sheets is based upon a modified version of the Brown surfacescattering model. The algorithm uses a five- or nineparameter model where one parameter in either model is the leading-edge width. A plot of the r.m.s. surface roughness from the combined model and the leading-edge width from the Martin and others (1983) algorithm vs longitude is shown in Figure 10. The maxima and minima in the $\sigma_{\mathbf{s}}$ plot are identical to those observed in the plot of the leading-edge width. Since the results presented above demonstrate that the return wave forms are dominated by volume-scattering, the one-to-one correspondence between the two plots is surprising, given that Martin and others' algorithm is based upon a surface-scattering model only. The probable reason that Martin and others' algorithm agrees so closely with the $\sigma_{\mathrm{s}}$ values from the combined model is that Martin and others' algorithm weights the leading edge of the return wave form heavily. The effect of this is that the nine-parameter surfacescattering model accurately fits volume-scattering wave forms, even though it was originally intended to fit complex wave forms resulting from two different scattering surfaces in the altimeter footprint. At this point, there is no basis for evaluating the relationship between $\sigma_{\mathrm{s}}$ and the true variation of surface roughness. However, a comparison between the surface roughnesses from the Greenland and Antarctic data sets shows that the average surface roughness from the Antarctic data set is nearly twice that observed in the Greenland data set. Qualitatively, this suggests that the wind intensities over this region of the Antarctic ice sheet are greater than those over the Greenland ice sheet. Clearly, further work in this 

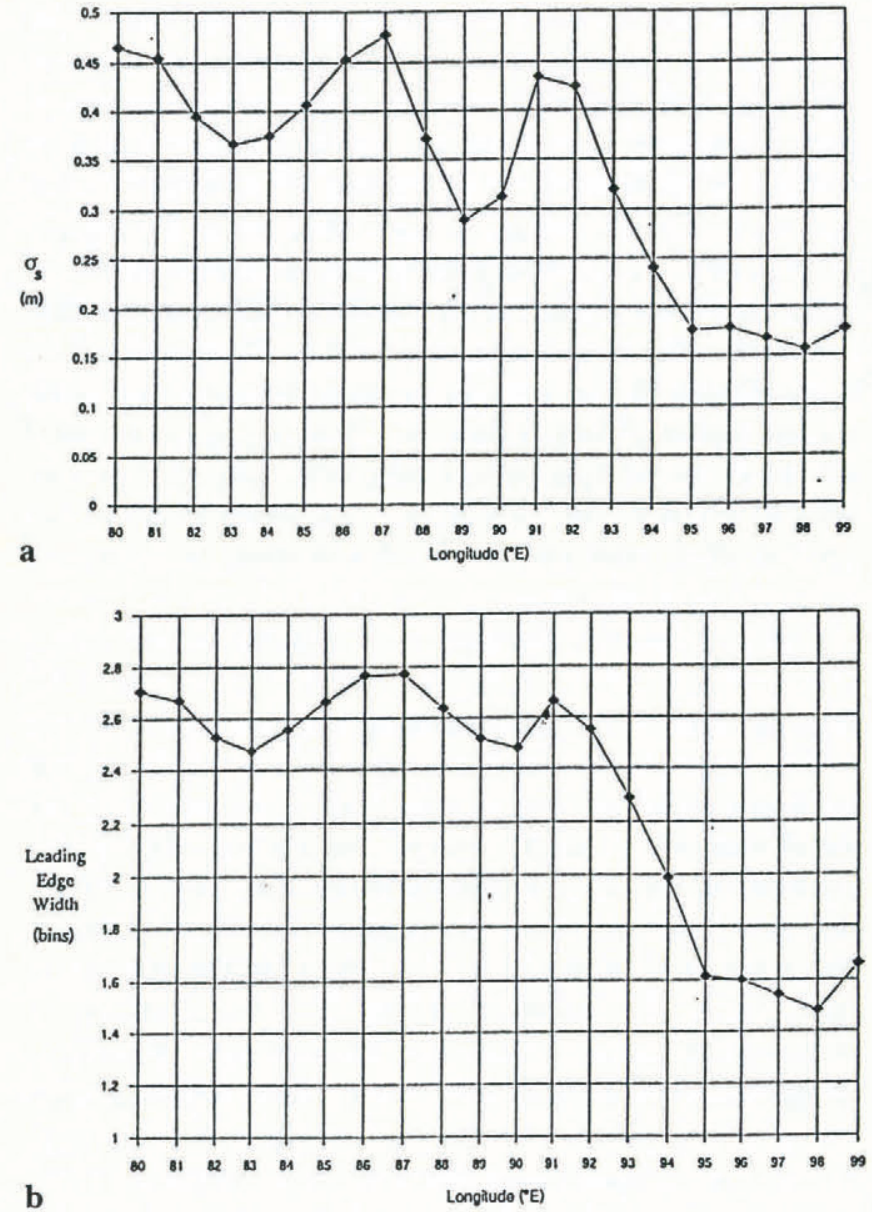

Fig. 10. (a) r.m.s. surface roughness vs longitude from the combined model for the summer season of 1986. (b) Leading-edge width vs longitude from Martin and others' (1983) model for the summer season of 1986.

area needs to be done, including independent measurement of surface roughness.

\section{GONGLUSION}

Seasonal and geographic variations in the surface properties of the ice sheet are estimated by fitting a surface- and volume-scattering model to individual altimeter return wave forms. Specifically, surface-scattering dominates the return wave forms in the low-latitude regions of the Greenland ice sheet, while sub-surface volume-scattering increases with latitude and elevation. The number of melt d year ${ }^{-1}$ for the southern Greenland ice sheet is determined from passive-microwave data. The variations in the extinction coefficient and volume coefficient correlate with surface melting. As the amount of surface melting decreases with increasing latitude, the extinction coefficient decreases. The decrease in the extinction coefficient indicates greater penetration of the altimeter signal into the snow, an increase in the volume coefficient and a greater volume-scattering contribution to the return power. For the East Antarctic ice sheet, the extinction coefficient varies with surface elevation and distance from the coastline. In the absence of surface melting, the average grain-size is related to the mean annual surface temperature because warmer temper- atures produce larger average grain-sizes. The colder temperatures associated with an increasing surface elevation produce smaller average grain-sizes so that the extinction coefficient decreases. Interpretations of the altimeter data and the passive-microwave data are consistent. Thus, even in the cold and dry conditions typical of East Antarctica, significant variations in extinction coefficient exist.

The significance of the results is three-fold. First, by repeated measurement of the combined model parameters, temporal changes in the surface conditions brought about by climatic variations in the polar regions could be observed. For instance, an increase in mean surface temperatures in Greenland would cause surface melting to occur in higher latitudes of the ice sheet. This would cause a decrease in the amount of sub-surface volume-scattering and would be reflected by significant changes in the extinction and volume coefficients. Also, this technique has the potential for monitoring changes in the location of the percolation and dry-snow zones in Greenland. Secondly, the extinction-coefficient variation with latitude, elevation and distance from the coast should be considered when analyzing active- and passivemicrowave data from the polar ice sheets. This relates directly to the amount of signal penetration beneath the surface of the ice sheet. Finally, the observed seasonal variations in the surface properties of the ice sheet may affect the accuracy of elevation measurements produced by various retracking algorithms. Elevations produced by various retracking algorithms should be compared with those from the combined model to quantify the effect of seasonal variations in the surface properties on the measurement of surface-elevation change. This is important for accurately measuring the mass balance of the ice sheets using radar-altimeter data.

\section{AGKNOWLEDGEMENTS}

The first author (C.H.D.) was supported by the NASA graduate student fellowship program grant No. GSRPNGT-50464, and additional funding was supplied by NASA/GSFC grant No. NAG-5-1464. Both authors. wish to thank R. Spurlock, A. Brenner, S. Fiegles and T. Seiss for assistance with computer programming and data processing, and R.K. Moore for discussion and useful comments.

\section{REFERENCES}

Benson, C.S. 1962. Stratigraphic studies in the snow and firn of the Greenland ice sheet. SIPRE Res. Rep. 70.

Bindschadler, R. A., H.J. Zwally, J. A. Major and A. C. Brenner. 1989. Surface topography of the Greenland ice sheet from satellite radar altimetry. Washington, DC, National Aeronautics and Space Administration. (NASA SP-503.)

Brooks, R. L., W. J. Campbell, R. O. Ramseier, H. R. Stanley and H.J. Zwally. 1978. Ice sheet topography by satellite altimetry. Nature, 274(5671), 539-543.

Chang, T. C., P. Gloersen, T. Schmugge, T.T. Wilheit and H.J. Zwally. 1976. Microwave emission from snow and glacier ice. $\mathcal{F}$. Glaciol., 16(74), 23-39.

Comiso, J. C., H.J. Zwally and J.L. Saba. 1982. Radiative transfer modeling of microwave emission and dependence on firn properties. Ann. Glaciol., 3, 54-58. 
Davis, C.H. In press. A surface and volume scattering retracking algorithm for ice sheet satellite altimetry. IEEE Trans. Geosci. Remote Sensing.

Davis, C.H. and R. K. Moore. 1993. A combined surface- and volumescattering model for ice-sheet radar altimetry. F. Glaciol., 39(133), $675-686$.

Davis, C. H. and V. I. Poznyak. In press. The depth of penetration in Antarctic firn at $10 \mathrm{GHz}$. IEEE Trans. Geosci. Remote Sensing.

Gow, A.J. 1969. On the rates of growth of grains and crystals in South Polar firn. J. Glaciol., 8(53), 241-252.

Gow, A.J. 1971. Depth-time-temperature relationships of ice crystal growth in polar glaciers. CRREL Res. Rep. 300.

Hayne, G.S. 1977. Initial development of a method of significant waveheight estimation for Geos-3. Washington, DC, Applied Science Associates, Inc. (NASA CR-141425.)

Hayne, G.S. 1981. Radar altimeter waveform model parameter recovery. Washington, DC, National Aeronautics and Space Administration. (NASA Tech. Memo. 73294.)

MacArthur, J. L. and others. 1987. The Geosat radar altimeter. Fohns Hopkins APL Technical Digest, 8, 176-181.

McGoogan, J. T., L. S. Miller, G. S. Brown and G. S. Hayne. 1974. The S-193 radar altimeter experiment. Proc. IEEE, 62, 793-803.

Martin, T. V., H.J. Zwally, A.C. Brenner and R.A. Bindschadler. 1983. Analysis and retracking of continental ice sheet radar altimeter waveforms. 7. Geophys. Res., 88(C3), 1608-1616.

Nye, J.F., Chairman. 1975. Symposium on Remote Sensing in Glaciology. General discussion. 7. Glaciol., 15(73), 437-453.

Partington, K. C., J. K., Ridley, C. G. Rapley and H.J. Zwally. 1989. Observations of the surface properties of the ice sheets by satellite radar altimetry. F. Glaciol., 35(120), 267-275.

Remy, F., C. Brossier and J. Minster. 1990. Intensity of satellite radaraltimeter return power over continental ice: a potential measurement of katabatic wind intensity. F. Glaciol., 36(123), 133-142.

Ridley, J.K. and K. C. Partington. 1988. A model of satellite radar altimeter return from ice sheets. Int. J. Remote Sensing, 9(4), 601-624. Robin, G.deQ. 1966. Mapping the Antarctic ice sheet by satellite altimetry. Can. J. Earth Sci., 3(6), 893-901.

Rotman, S.R., A.D. Fisher and D.H. Staelin. 1982. Inversion for physical characteristics of snow using passive radiometric observations. F. Glaciol., 28(98), 179-185.

Somma, R. and others. 1981. Radar altimeter phase. A final report. Noordwijk, European Space Agency. (ESA Contract Report CR(P) 1514.)

Stanley, H. R. 1979. The Geos 3 project. F. Geophys. Res., 84(B8), 37793783.

Thomas, R. H. 1991. Polar research from satellites. Washington, DC, Joint Oceanographic Institutions, Inc.

Townsend, W.F. 1980. An initial assessment of the performance achieved by the Seasat-1 altimeter. IEEE J. Oceanic Eng., 5, 80-92.

Zwally, H.J. 1977. Microwave emissivity and accumulation rate of polar firn. 7. Glaciol., 18(79), 195-215.

Zwally, H.J. 1989. Growth of Greenland ice sheet: interpretation. Science, 246(4937), 1589-1591.

Zwally, H.J. and P. Gloersen. 1977. Passive microwave images of the polar regions and research applications. Polar Rec., 18(116), 431-450.

Zwally, H.J., R.A. Bindschadler, A. C. Brenner, T. V. Martin and R.H. Thomas. 1983. Surface elevation contours of the Greenland and Antarctic ice sheets. J. Geophys. Res., 88(C3), 1589-1596.

Zwally, H.J., A. C. Brenner, J. A. Major, R. A. Bindschadler and J. G. Marsh. 1989. Growth of Greenland ice sheet: measurement. Science, 246(4937), 1587-1589.

Zwally, H.J., A. C. Brenner, J.A. Major, T. V. Martin and R.A. Bindschadler. 1990. Satellite radar altimetry over ice. Vol. 1. Processing and corrections of Seasat data over Greenland. Washington, DC, National Aeronautics and Space Administration. (NASA Ref. Pub. 1233, 1.)

The accuracy of references in the text and in this list is the responsibility of the authors, to whom queries should be addressed. 